\section{Importance of establishment of corporate culture in libraries in the development of information services}

\section{Bilgi hizmetlerinin gelişmesinde kütüphanelerde kurum kültürünün oluşmasının önemi}

\author{
Mustafa Bayter ${ }^{1}$
}

\begin{abstract}
Institutions carry the reflections of the culture in which they are formed. Therefore, each institution is influenced by its cultural structure in order to create its own culture. This corporate culture consists of values, beliefs and norms that hold the members of the institution together. Libraries are the institutions with the most important sources of information. The longer the corporate culture is established within this organization, the more effective the access to information and communication with the user will be. In this context, the subject of our study, the definition and history of corporate culture, the formation of corporate culture, the place and importance of culture in the institution, the elements of corporate culture, corporate culture and corporate change, corporate culture and management, the effect of managers in the formation of corporate culture, corporate culture and human resources, corporate culture culture and institutional commitment, the formation of institutional culture in the library institution, library and institutional behavior, library and institutional culture, the effect of the library on the formation of corporate culture.
\end{abstract}

Keywords: Institution, Culture, Communication, Corporate Culture, Library and Corporate Culture.

(Extended English summary is at the end of this document)

\section{Özet}

Kurumlar, içinde oluştukları kültürün yansımalarını taşırlar. Bu yüzden her kurum kendi kültürünü oluşturabilmek için içinde bulunduğu kültür yapisından etkilenmektedir. Kurumsal kültür, kurum üyelerini bir arada tutan değerler, inanç, normlardan meydana gelmektedir. Kütüphaneler bilgi aktarımını sağlayan en önemli bilgi kaynaklarına sahip kurumlardır. Kütüphane kurumu içerisinde kurum kültürü ne kadar iyi oluşursa bilgiye ulaşım ve kullanıcı ile olan iletişim o kadar etkili olacaktır. Bu çalışmada bilgi hizmetlerinin gelişmesinde kütüphanelerde kurum kültürünün oluşmasının önemi, kurum kültürünün tanımı ve tarihçesi, kurumsal kültürün oluşmas1, kültürün kurumdaki yeri ve önemi, kurum kültürünü oluşturan unsurlar, kurum kültürü ve kurumsal değissim, kurum kültürü ve yönetim, kurum kültürünün oluşmasinda yöneticilerin etkisi, kurum kültürü ve insan kaynakları, kurum kültürü ve kurumsal bağlllık, kütüphane kurumunda kurumsal kültürün oluşumu, kütüphane ve kurumsal davranış, kütüphane ve kurum kültürü, kütüphanenin kurum kültürü oluşturmasındaki etkisi başlıkları altında incelenmeye çalışılmıştır.

Anahtar Kelimeler: Kurum, Kültür, İletişim, Kurum Kültürü, Kütüphane ve Kurum Kültür.

\footnotetext{
1 Dr. Öğ. Üyesi. Ankara Yıldırım Beyazıt Üniversitesi İnsan ve Toplum Bilimleri Fakültesi Bilgi ve Belge Yönetimi Bölümü, mbayter@hotmail.com
} 
Bayter, M (2019). Bilgi hizmetlerinin gelişmesinde kütüphanelerde kurum kültürünün oluşmasının önemi. Journal of Human Sciences, 16(3), 844-856. doi:10.14687/jhs.v16i3.5771

\section{Giriş}

Yaşadığımız bu bilgi çağında bilgiye daha hızlı ve daha güvenli ulaşımın sağlanması, bilgi ihtiyacının karşlanması toplumsal ve kültürel başarının olmazsa olmazıdır. Bilgiye ulaşma süreçleri de insanlar arasında bir etkileşime ve iletişime neden olmaktadır. Kütüphane kurumunun temel işlevi de kişilerin bilgi ihtiyacını karşılamaktır. Her kurumda olduğu gibi kütüphane içerisinde de bir kurum kültüründen bahsetmek mümkündür. Kütüphane içerisinde kurum kültürünün olması çalışanlar arasındaki iletişim, beklentiler, ortak değerler, ortak amaç, tutum ve davranışlar sonucu oluşmaktadır. Oluşan bu kültür sayesinde kütüphane kullanıcılarının ihtiyaç ve beklentilerini karşlamada daha başarılı olunur ve kullanıcı ile sağlıklı iletişimin temelleri oluşturulur. Kurum kültürüne sahip bir kütüphane, kullanıcı ihtiyaçlarını karşılamada planlı ve programlı hareket eder. Bunun sonuncunda da kütüphanede verilen bilgi hizmetleri gelişir ve kütüphane kurumu da toplumun bilgi ihtiyacını karşılamada başarılı olur.

\section{Amaç ve Metod}

$\mathrm{Bu}$ çalş̧madaki amaç; bilgi hizmetlerinin gelişmesinde kütüphanelerde kurum kültürünün oluşmasının önemini vurgulamaktır. Çalışmada var olan durumu ortaya çıkarabilmek için betimleme yöntemi kullanılmıştır. Betimleme yöntemi; "olaylanı obje ve problemleri anlama ve anlatmada ilk aşamayı oluşturur. Bilimsel etkinlikler olayların betimlenmesiyle başlar. Bu sayede onları iyi anlayabilme, gruplayabilme olanağı saptanır ve aralarındaki ilişkiler anmış olur.” (Kaptan, 1998: 59)

\section{Kurum Kültürünün Tanımı ve Tarihçesi}

Kurum kültürü kavramı için tek bir tanımdan bahsetmek mümkün değildir. Psikoloji, sosyoloji, antropoloji, yönetim, iletişim vb. birbirinden farklı disiplinler tarafindan yorumlanması ve çalışılması ile birbirinden farklı kurum kültürü tanımı ortaya çıkmıştır (Durğun, 2006: 112). Kurum kültürü, kurumdaki bireylerin davranışlarını yönlendiren normlar, değerler, inançlar ve alışkanlıklar sistemidir. Başka bir deyişle kurum kültürü, çalışan kişilerin kurum bütünleşmesini sağlayan değerler ve inançlardır (Önal ve Ekici, 2012:139).

Literatürde çok sık geçen kurum kültürü tanımını Schein (1990) şu şekilde yapmışır. Kurum çalışanlarının gerek çevreye uyumu gerekse kurum içi bütünleşmesi sırasında öğrendiği geçerliliği kanıtlanacak düzeyde olumlu sonuç vermiş olan ve bu nedenle yeni gelenlere programları algılamanın, düşünmenin ve hissetmenin doğru yolu olarak öğretilen, bir takım değerlerdir. Kurum kültürü; kurum içinde çalışan grupların keşfettiği, geliştirdiği temel fikirler ve düşünceler olarak da tanımlanmıştır. Bu tanımda kültürün iki temel fonksiyonu saptanmaktadır. İç çevrede uyum sağlamak ve dış çevreye grubun uyumunu sağlamak. İç bağlllı̆̆ kolaylaştırmak için kültür;

-Kurum çalışanlarının dil, ortak ifade ve kavramları sağlanmalı

- Kişilerin kurumdaki yeri belirlenmeli

•Güç ve statünün dağılımı, çalışanlar arası ilişkiler ve ödül-yaptırım sistemini ve tüm organizasyonel olaylara bir anlam veren kurumun amacı anlatılmalıdır.

Kullanıcı ihtiyaçlarını karşılama konusunda ise kütüphanenin kurum kültürü; stratejisini ve misyonunu, kurumun amaçlarını ve bu amaçlara ulaşmak için izlenecek yolları tanımlamalıdır. Literatürde geçen ve sıklıkla kullanılan diğer bir tanımda Hofstede’e aittir. Hofstede' e (2010) göre kurum kültürü; her kurum çalışanının bir diğerine farklılık gösteren, aklın kolektif bir şekilde programlanmasıdır. Bakan vd.'e göre kurum kültürü; bir grubun veya bir kurumun çalışanlarının ortaklaşa paylaştıkları ve kabul ettikleri, onların davranışlarını yönlendiren ve gelenekselleşmiş normlar, davranışlar, değerler ve inançlardan oluşan temel semboller ve uygulamalar bütünüdür (Bakan vd, 2004: 20).

Kurum kültürü ilk kez 1939 yılında Lewin, Lipit White (1939) tarafindan liderlik tarzları ve kurum iklimi arasındaki ilişkinin araştırılması ile ele alınmıştır. 1973 yılındaki OPEC petrol krizi ve artan uluslararası ilişkiler nedeniyle dünya güçlerindeki dengelerin değişmesi kültür ve kurum arasındaki ilişkiyi anlama konusundaki ilgiyi artırmıştır (Satuk, 2006:58). Ancak tam anlamı ile kurum 
ve yönetim alanındaki kurum kültürü kavramının kullanımı 1980’li yıllarda olmuştur. Kurum kültürü kavramının yaygınlaşması ve literatüre girmesini sağlayan, 1982 yılında yapılmış iki çalışma etkili olmuştur. 'Deal ve Kennedy'nin 'Kurum Kültürü'(2000) adlı kitabı ile Peters ve Waterman'ın 'Mükemmeli Arayış' (1995) adlı kitabı' kurum kültürü kavramının oluşmasını ve yaygınlaşmasını sağlayan çalışmalar olmuştur.

\section{Kurumsal Kültürün Oluşmas1}

Kurumsal kültürün oluşturması için psikoloji, sosyal psikoloji, sosyoloji ve antropoloji gibi davranış bilimlerinden yararlanılır. Çalışanların; öğrenme, motivasyon, kişilik, duygular, algı, eğitim, liderlik, etkinlik, bireysel olarak karar verebilme, performans değerlendirme, tutum ölçümü, çalş̧an seçimi, iş tasarımı, iş stresi gibi davranışları inceleyerek, bu alanlara özgü getirilen yorumlar ile kurumsal kültürün oluşması sağlanır. Kurumsal kültürün oluşmasında, çalışanlardaki davranış değişiklikleri, tutum değişiklikleri, iletişsim, grup süreçleri, grup olarak karar verebilme potansiyellerini incelemektedir. $\mathrm{Bu}$ sayede de çalışanlar içerisinde kurumsal davranış disiplini oluşturmayı hedeflemektedir.

Sosyoloji bilimine göre kurumsal kültürün oluşmasını; iletişim, güç, çatışma, gruplar arası davranış unsurları, klasik kurum teorisi, kurumsal teknoloji ve kurumsal değişim sağlamaktadır. Kurumun gelişmesi, hem kurum hem de kurum çalışanları için uygun şartların sağlanması ve bir kurum sisteminin oluşması için yön göstermektedir. Antropoloji ise kurum sistemi içerisinde yer alan; mukayeseli değerler, mukayeseli tutumlar, kültürlerarası analizler yaparak kurum içerisinde kurum kültürü oluşturmaya çalışır ( Robbins ve Judge, 2013: 13). Bu disiplinlerin her biri kurum içinde bir kurumsal kültür oluşturabilmek için kuruma katkıda bulunup bilgi birikimi sağlamaktadırlar. Kurumsal kültür bireyler, gruplar ve yapılar üzerinde çalışır. Kurumsal kültürün üzerinde çalıştığı bu üç öğe, kurum içerisindeki politikaları belirlemektedir.

Kurum kültürünün oluşmasında etkili olan üç görüş öne çıkmaktadır. Bu görüşler:

- Kuruluş aşamasında kurum kurucularının oynadığı rollerden kaynaklanması,

- Çalışanların iç bütünleşme ve çevreye uyum sorunlarını çözmek amacıyla girdikleri etkileşiminden kaynaklanmas1,

- Kurum çalışanlarının, kurum kimliği, denetim, bireysel ihtiyaçlar ve kabul görme sorunlarına yönelik geliştirdikleri çözümlerin oluşturduğu durumlardan kaynaklanır (Fidan, 2011: 11).

Kurum kültürünün oluşmasında en önemli rol kurum yöneticisine düşmektedir. Çünkü yönetici, kurumun kalıcı olmasını sağlamak için kurumda çalışan bireyler tarafından benimsenmeli, onlar için iyi bir yol gösterici olabilmeli, kalıc1 olup geçerliliğini yitirmeyecek bir sistem oluşturabilmelidir. Çalışanlar için iyi bir rol modeli olmalı ve çalışanları motive edebilmelidir. Kurum içerisinde takım ruhunu oluşturabilmeli, çalışanlara birlik ve beraberlik ruhunu aşılayabilmelidir (Önal ve Ekici, 2012, 139).

\section{Kurumsal Kültür- Mesleki Kültür}

"Bir işletme, kurum ve örgüte ait olana kurumsal kültür; bir meslek etrafinda birleşenlerin meydana getirdiği topluluğa ait olana ise mesleksel kültür denir” ( Tural, 2009: 13).

\section{Kültürün Kurumdaki Yeri ve Önemi}

Canlı organizmalar nasıl ki hayatta kalmak için mücadele ediyorlarsa, kurumlar da varlıklarını sürdüre bilmek için mücadele etmek zorundadır. Böyle bir mücadele içerisinde farklı kültür yapılarına sahip çalışanlardan oluşan kurumlar, çalışanları kurumsal hedefe yönlendirir. $\mathrm{Bu}$ yüzden de kurumun hedeflerinin, amaçlarını gerçekleştirmesinin, strateji ve planlarının, politikalarının oluşmasında, başarısında ve uygulanmasında kültür önemli bir etkiye sahiptir. $\mathrm{Bu}$ kültürel unsurların bilinmesi kurum için oldukça önemlidir.

Kurum mutlaka, oluşturulacak kurum kültürünün çalışanların verimine olumlu katkıda bulunabileceğini hesaba katmalıdır. Her kurumun kendi kurallarını, geleneklerini, göreneklerini ve 
Bayter, M (2019). Bilgi hizmetlerinin gelişmesinde kütüphanelerde kurum kültürünün oluşmasının önemi. Journal of Human Sciences, 16(3), 844-856. doi:10.14687/jhs.v16i3.5771

bunlarla da kültürünü yarattı̆̆ söylenebilir. Etkin kurumların mükemmel olmanın önemini artıran iç kültürlere sahip olduğu söylenebilir(Satuk, 2006: 54).

Kurum kültürünü etkileyen üç temel öğe vardır. Bu üç temel öğe kültürel sistem, sosyoyapısal sistem ve birey unsurudur. Sözkonusu öğeler şu şekilde açıklanmaktadır:

1. Kültürel sistem kurumun ideolojisini, değerlerini, hikaye, tören ve adet gibi olgularını içermekte ve kurum içinde paylaşılan önemli sembolleri açıklamaktadır.

2. Sosyo-yapısal sistem ise kurumun amaçlarına ulaşması için gerekli olan biçimsel ilişkileri, yapıyı, strateji, politika ve süreçleri içermekte ve kurumdaki yetki-güç hiyerarşisi, ödül sistemleri ve denetim mekanizmalan bu sistem içerisinde yer almaktadır.

3. Birey unsuru ise kurumdaki çalışanların kişisel deneyimlerini, kişilik özelliklerini, yetenek ve becerilerini kapsar (Uslu, 2010:15).

\section{Kurum Kültürünü Oluşturan Unsurlar}

Kurum kültürünün oluşumuna bakıldığında iki şekilde olduğu görülmektedir. Kurum kültürü ya kendiliğinden zaman akışı içerisinde oluşur ya da oluşturulur. Ortaya çıkan bu kültürün amacı çalışanların hedeflerinin ve kurumsal amaçlarının gerçekleşmesi bunun sonucunda da kurumsal bağlılığın oluşmasıdır. Bu kültürü oluşturan bir takım sembol ve ifadeler vardır. Bu sembol ve ifadeler kültür ile kurum arasında bir bağ kurmakta ve bütünlük sağlamaktadır. Bu bütünlüğü koruyabilmek için sembol ve ifadelerin, çalışanlar tarafindan benimsenmesi, çalışanların sembollerle bütünleşmesi gerekmektedir. Bütünleşme zaman içerisinde de çalışanlar tarafindan yenilenir. Dolayısıyla kültür, bireylerde kalıtım veya içgücü sonucu ortaya çıkan bir unsur değildir. Kültür, bireylerin yaşantıları sonucunda edindikleri tecrübeler, eğilimler, alışkanlıklar, davranış ve tepkilerin tümüdür. Bu yüzden de kültürün oluşabilmesi için eğitim ve öğrenme çok önemlidir ( Erdem ve Dikici, 2009: 207).

Kurum kültürü birçok unsurun bir araya gelmesiyle oluşan bir bütündür. Bu unsurlara kısaca değinilecek olursa;

Temel Değerler: Kurum kültürü içerisindeki değerler, iş görenlerin çalışmalarını, eylemlerini nitelendirmeye ve değerlendirmeye yarayan ölçütlerin kaynağı ve kurumda neyin istenir, neyin istenmez olduğunun belirleyicisidir (Erdem, 2003: 56).

Normlar: Normlar, kurumda karşllıklı olarak neyin doğru neyin yanlış olduğu hususundaki anlaşmalar, genel kabul görmüş standartlardır (Değirmenci, 2007:136). Normlar açıkça dile getirilmezler, yazılı değildirler, öğrenilebilir nitelik taşırlar, zamanla alıskanlık haline gelirler ve kurum üyelerinin davranış biçimleri üzerinde önemli etkiye sahiptirler (Sabuncuoğlu, Tüz, 1998: 37).

İnançlar: İnançlar, kurum içinde neye inanılıp neye inanılmayacağını belirten değerlerdir. Kurumun üyelerinin sahip olduğu inançlar kurum kültürünün oluşumunu ve devamlıllğını sağlayan temel unsurlardır (Bakan vd., 2004: 42). Herhangi bir kurumun yaşamını sürdürebilmesi ve başarllı olabilmesi için, tüm politika ve eylemlerini de içeren, bir dizi sağlam inancının olması gerekir (Peters, Waterman, 1987: 383).

Varsayımlar: Kurum içinde sorunlar sürekli olarak belirli bir şekilde çözüme ulaşturllnnca, bu sorunların çözümü ya da çözüm şekli, bilinç düzeyinden bilinçaltı düzeyine inmekte ve bu çözümler diğer sorunların çözümünde sorgulanmadan, en iyi çözüm olarak kullanılmaktadır. Bunlara varsayım adı verilmektedir (Değirmenci, 2007: 137). Varsayımların en önemli özelliği ise tartışmaya açık olmamalar1 ve sorgulamadan kabul edilmeleridir (Schein, 2004: 21).

Hikayeler: Kurumsal hikayeler, kurumun kökeni, vizyonu ve misyonunu içerir, tüm organizasyon hakkında kapsamlı bir anlatı sunmayı amaçlar ve kurumun kilit yönlerini gerçekçi ve uygun şekilde açıklar (Balmer, Greyser, 2003:143).

Mitler: Kurum mitleri, kurumsal hayata canlılık katmak, beraberliği sağlamak adına anlatılan efsanelerdir. Kurum mitleri, eski olanlara kim olduklarını ve neye inandıklarını hatırlatır, yeni gelenlere de o kuruma mensup olmanın ne anlama geldiğini öğretir (Cohen, Prusak, 2001: 164).

Liderler ve Kahramanlar: Liderler kurum kültürüne katkıda bulunan, çalışanları motive eden, kurumu ve onun kültürünü dışarıya karşı temsil eden en yüksek yönetim kademesindeki kişilerdir 
Bayter, M (2019). Bilgi hizmetlerinin gelişmesinde kütüphanelerde kurum kültürünün oluşmasının önemi. Journal of Human Sciences, 16(3), 844-856. doi:10.14687/jhs.v16i3.5771

(Kozlu, 1986: 67). Liderler kuruluşlarını rekabet avantajı elde etmek üzere konumlandırarak, kültürlerin değiştirilmesi ve geliştirilmesi için gereken ilhamı sağlayabilirler (Goffee, Jones, 2002: 35). Kahramanlar ise kurumun değerlerini ve kültürünü kişiliklerinde somutlaştıran kişilerdir. Kurum içinde her üyenin bireysel performansını örnek aldığ1 kişiler olan kahramanlar aynı zamanda ulaşılabilir bir kişiliği de temsil ederler (Sabuncuoğlu, Tüz, 1998: 38).

Semboller: Semboller; kurumun varlığının ve yaşamının görünen yönünü temsil ederler ve kurumun işareti olarak kullanılan objeler, logolar, flamalar, ünvanlar, giysiler, binaların mimarisi, büroların düzenlenmesi örnek olarak gösterilebilir (Cansu, 2006: 17). Bu semboller kimin önemli olup kimin olmadığ1, yöneticilerin ne kadar eşitlik istedikleri ve uygun olan davranışlanın neler olduğu gibi konularda ipucu vermektedir (Schermerhorn vd., 2008: 272).

Törenler: Törenler kurum kültürünün bir kutlama aracı olup, kurum içindeki kültürel değerleri pekiştirmeyi, üyeler arası bağlllı̆ı arttırmayı hedefler (Cansu, 2006: 16).

Dil: Dil kültürün en önemli parçası ve taşıyıcısıdır. Bu temel eleman kültürün öğrenilmesine, manaların simgelenmesine yardımcı olur (Çağlar, 2001: 131). Kurumlar veya kurumların alt birimlerinin, işlerini ve terminolojilerini tanımlamak için geliştirdikleri kendilerine özgü kurumsal dil, kültürün desteklenmesine yardım eder ve o kültüre ait bireyleri bir arada tutmaya yarayan ortak bir faktör olarak hizmet eder (Greenberg, Baron, 1990: 545, aktaran Şişli ve Köse, 2013: 167).

\section{Kurum Kültürünün Değişimi}

Kurumlar yaşamlarını devam ettirebilmek için bilgiyi kullanmalı, bilgi üretebilmeli ve bu bilgiyi paylaşabilmelidir. Bunun sonucunda da büyümeyi, rekabet edebilmeyi umut ediyorsa değişimi ve gelişimi, yenilenmeyi göze almalıdır (Muratoğlu ve Özmen, 2006 : 6).

Deal ve Kennedy (2000) kurum kültüründeki değişimin nedenlerini şu şekilde ifade etmektedirler :

- Kurumun değişen çevreye uyum sağlayamayan güçlü değerlere sahip olması,

- Çevrenin çok rekabetçi olması ve hızlı değişmesi,

- Kurumun performans açısından kötü veya ortalama bir seyir izlemesi,

- Kurumun çok daha büyük örgütler sinıfina katılması,

- Kurumun hızlı bir şekilde büyümeye başlaması.

R. Kilmann’a (1985) göre ise kurumdaki değişimin nedeni dörde ayrılmaktadır. Bunlar:

1. Kurum kültürü, kurumun ana hedefini destekler nitelik arz etmiyorsa,

2. Kurum kültürü, kurumun başarısını itici bir güç olarak harekete geçirmiyorsa,

3. Kurum kültürü, kurumdaki çıkar grupları arasında uyum sağlamıyorsa,

4. Kurum kültürü, kurum üyelerine kurumun karmaş1k ve zor sorunlarını ele almaya ve çözmeye yönlendirici katılımcı bir ortam sağlamadığı hallerde kurum kültürü değişikliğe uğrar.

\section{Kurum Kültürü ve Yönetim}

Beşeri bir yöne sahip olan yönetim kavramı çok boyutlu bir kavramdır. Yönetim alanında da bir sürü tanım yapılmıştır. Kimi işlerin insan aracılı̆̆ıla yaptırılması, kimi de istenilen amaçları gerçekleştirebilmek için kaynakların etkin ve yeterli bir şekilde birleştirilmesi ve koordine edilmesi olarak tanımlamıştır (Şahin, 2010: 26). Yönetim sürecinde kutsal üçlü olarak kabul edilen planlama, örgütleme ve kontrol etme fonksiyonları değişmiş, bunun yerine amaçları saptama, motivasyon, iletişimi sağlama, değerlendirme, eğitim, vizyon, destek verme, liderlik, delegasyon, yaratıcıllk ve sorun çözme" kavramları etkili olmuş ve daha sık kullanılmaya başlanmıştır(Şahin, 2010: 28). Yönetim süreci kapsamında yöneticiler, kurum içerisindeki formal ve informal yapıyı da etkilemekte ve kurumsal davranışın temelini oluşturmaktadırlar. Kurumsal davranışın gerçekleşmesi ise kurum kültürü vasıtası ile mümkün olmaktadır. 
Bayter, M (2019). Bilgi hizmetlerinin gelişmesinde kütüphanelerde kurum kültürünün oluşmasının önemi. Journal of Human Sciences, 16(3), 844-856. doi:10.14687/jhs.v16i3.5771

\section{Kurum Kültürünün Oluşmasında Yöneticilerin Etkisi}

Kurum yönetimine gelen yöneticilerin amacı kurum bünyesindeki insanların kurumun amaçlarını ve hedefini doğru bir şekilde anlamalarını sağlamak, kurum içerisinde birlik ve beraberlik ortamı oluşturarak bir kurum kültürü oluşturmayı sağlamak olmuştur. Yöneticiler, kurumun ve kurum kültürünün devamı için, çalışanların duygu ve düşüncelerine önem vermeli, çalışma ortamını çalışanları motive edecek şekilde düzenlemeli ve kurum çalışanları için iş doyumu sağlayabilmelidir. İş doyumu olmayan, çalışma ortamını, grup arkadaşlarını sevmeyen, sürekli tartışma ve çatışma ortamlarına maruz kalan çalışanlar kuruma olan güvenini kaybetmektedir. Kurum içerisinde devamlılığı sağlamak çalışanların kurumun hedeflerini, beklentilerini anlamaları ve bu beklentilerin çalışanların beklentileri ile uyuşması yolu ile olmaktadır. Ancak çalışanların beklentilerine olumlu yanıtlar veren kurumda çalışanlar aynı beklentileri istemektedir. Ĕger çalışanlar kurum başarısını sağlayan davranışlarda bulunurlarsa kurum tarafindan ödüllendirilmelidir. Fakat bunun tam tersi olduğunda da yani çalışan kurumun huzurunu ve devamlılı̆ıını bozacak bir faaliyette bulunursa da hemen cezalandırılmalıdır. Bu ceza ve ödül kurum kültürünü güçlendirmektedir.

Kurumun devamlllı̆̆1 sadece kurum içerisinde bir kültür oluşturmak ile olmamaktadır. Kültürün yanı sıra etkili iletişim, halkla ilişkiler, kurum ve toplum arasındaki ilişki, insan kaynakları da kurum ve kurum kültürü için önem arz etmektedir. Yönetici iletişim alanında iyi olmalıdır. İletişimi güçlü yöneticiler, kurum ve çalışanların beklentilerini anlayabilmekte ve bu beklentileri hızlı bir şekilde giderebilmektedir.

\section{Kurum Kültürü ve İnsan Kaynakları}

Kurum kültürünün ortaya çıkışı insan kaynakları ile ilgili yapılan araştırmalar sonucunda ortaya çıkmıştır. Bu yüzden bu iki kavram arasında oldukça sıkı bir ilişki vardır. İnsan kaynakları yöneticileri, kurum kültürünü oluşturan ritüeller, semboller, kurallar, inançlar ve davranışlar üzerinde de etkili olabilir ve bu kültürel unsurların değişiminde rol alabilirler. İnsan kaynakları, işe alma, performans değerlendirme faaliyetleri, ödül ve ceza işlemleri, hizmet içi eğitim seminerleri ile de kurum kültürünü doğrudan etkileyen bir yapıya sahiptir (Satuk, 2006: 85).

\section{Kurum Kültürü ve Kurumsal Bağl1lık}

Bağlllık kavramı toplum duygusunun getirdiği bir özelliktir. Bağlllık sözlükteki anlamına göre sadık kalma anlamına da gelmektedir. Bağlllık kavramını, bireylerce hissedilen en güçlü duygulardan biri olan bağlılık; aynı zamanda bir kişiye, bir düşünceye, bir kuruma ya da kendimizden daha büyük gördügümüz bir şeye karş1 gösterdiğimiz bağllliğ1 ve yerine getirmek zorunda olduğumuz bir yükümlülüğü ifade etmektedir ( Boyac1, 2010: 5).

Kurumsal bağlllikta, işe katılma, sadakat ve kurum değerlerine olan inançtan oluşan bu üç öğe bireyin kurum içindeki psikolojik bağlllığını ifade etmektedir. Bu bağlllıkta itaat, dahil olma ve kimlik kazanma olmak üzere üç faktörden meydana gelmektedir. İtaat aşamasında çalışan, kurum tarafindan kabul görmek amacıyla kurum içerisindeki diğer bireylerin etkisini kabul eder. Bağlliık, sadakat aşamasında ise grup tarafindan kabul gören çalışan, grup içerisinde olmaktan gururlanır ve gruba ait kültürü, kuralları, değerleri kabul edip benimser (Boyac1, 2010: 6).

\section{Kütüphane ve Kurum Kültürü}

Kurum kültürü; kurumdaki bireylere, birbirlerine karşı davranışları ve işlerin yapılma şekli konusunda rehber olan, bireylerarası etkileşimle ortaya çıkan ve paylaşılan inançlar, tutumlar, tahminler ve beklentiler modelidir (Armstrong, 1990: 206). Amacı kullanıcilarına bilgi hizmetleri sunmak olan kütüphaneler, bu amacı gerçekleştirmek için personel ve diğer bilgi kaynaklarını bir araya getiren hizmet kurumu olarak ele alınabilir. Kütüphane kurumunun amaçlarını gerçekleştirebilmesi, bilgi kaynaklarının belli ilke ve yöntemlerle harekete geçirilmesini sağlayan kurum kültürü ile mümkün olur. 
Kütüphane kurumunun amaçlarını gerçekleştirerek, insanlara hizmet edebilmesinde kurum kültürü, kurum bağllliğı, personel yönetimi ve memnuniyeti, kurumsal davranış ile kurumsal iletişimin rolü oldukça fazladır. İletişim sorunlarının gün sşı̆̆ına kavuşması ve öneminin anlaşılması endüstri devriminin kurumsal yapı üzerinde oluşturduğu gelişmeler ile başlar. Günümüzde uzmanlaşma, iş bölümü ve teknolojik gelişmeler sonucu, insancıl ilişkilerle iletişim sorunları geleneksel güçlüklerden soyutlanarak daha farklı boyutlar kazanmıştır. Teknolojik gelişmelerde çağdaş nitelik kazanan kütüphaneler kurum kültürü ile etkili bir yönetim anlayışının vazgeçilmez bir parçasını oluşturmaktadır (Üstün, 1997: 22).

Kurum kültüründe personel yönetimi, oldukça önemli bir kavramdır. Personel arasındaki iş birliğinin, güvenin, dostça ilişkilerin sağlanabilmesi gerekmektedir. $\mathrm{Bu}$ da personelin kurumsal bağlılık, kurum kültürü ve kurumsal davranışın oluşturulmasını sağlar. Bu nedenle yönetim, kurum içerisindeki temeli oluşturmaktadır. Kurumun gelişmesi, personelin çaba ve gayretlerinin bir sonucudur. Bu yüzden de kurum içerisinde insan kaynakları ve personel önemlidir. Personelin verimliliğini artırabilmek, personel becerisinin ortaya çıkarılması iyi bir yönetim faaliyeti sonucunda olmaktadır. Personel yönetimi, bir kurumun amacına ulaşmasını sağlamak üzere, kuruma personel sağlanması, eğitilmesi, geliştirilmesi, maddi bakımdan tatmini, kuruma uyumunun sağlanması, sağlık ve koruma güvencelerinin verilmesi gibi doğrudan insanla ilgili konularla ilgilenir. Bu doğrultuda her kütüphane bir takım, yönetim ve kültür özelliklerine sahiptir. Üniversite kütüphaneleri, okul kütüphaneleri, halk kütüphaneleri vb. kütüphane türlerinde yönetim ve personel yönetimi, kurum kültürünün oluşturulması açısından çok önemlidir (Çelik, 2014 :302).

Bütün kütüphanelerin amac1, dermelerini geliştirerek düzenlemek ve hizmete sunmaktır. Bunun için de kütüphanelerde yeterli sayıda personel olmalıdır. Kütüphaneye ait bir kültürün olması için personel doğru bir şekilde seçilmelidir (Çelik, 2014 :303). Seçilecek personelin sahip olmaları gereken özellikler vardır. Bunlar;

- Hızlı ve sürekli öğrenme,

- Bilgi kaynaklarının organizasyonu ve erişimi için yeni yollar arama,

- Yeni teknolojileri takip edebilme,

- Bireysel ve takım çalışmasına yatkın olma,

- Risk alabilme ve baskı altında çalışabilme,

- Kullanici merkezli olma,

- Değişim taraftarı olma,

- Yaşam boyu öğrenme odaklı olma,

- Araştırma yapabilme, yönetebilme ve sonuçlarını yayımlayabilme,

- Kütüphane hizmetlerini teknolojinin öngördüğü biçimde ve kullanıcıların beklentileri doğrultusunda düzenleyebilme,

- Bilgilerini meslektaşları ile paylaşabilme,

- Web teknolojilerini kütüphane hizmetlerine uyarlayabilme,

- Kütüphane hizmetlerini pazarlayabilme,

- Çevresindeki her şeyi sorgulayabilme becerileridir (Kurulgan ve Paşaoğlu, 2013: 54).

\section{Kütüphane Kurumunda Kurumsal Kültürün Oluşumu}

Bilginin hızla değişmesi doğal olarak bilgiyi ve bilgi kaynaklarını mevcudunda barındıran kütüphanelerin de bu yenilenme sürecine katılarak hizmetlerini en uygun şekilde sunması gereklidir. Sürekli güncellenen dünyada kurumların kendilerini yenileyebilmeleri kurumsal alt yapının yanında mevcut personelin mesleki ve kurumsal gelişim ve değişime kendilerini dâhil etmeleri ile gerçekleşecektir. Kütüphanelerin, hizmetlerini en iyi kalitede sunmak ve talep edilen bilgiye ulaşmada insanlara yardımcı olmak için; kurum kültürü çerçevesinde kurumsal verimliliklerini artırmalıdırlar (Dina ve Olowosoke, 2018). Kütüphaneler, kurumsal verimliliklerini artırabilmek için öncelikle daha etkili yönetilmelidir. Etkili ve verimli yönetmek için sadece yapı, süreç ve teknolojik değişiklikler yetmez. Başarının esas kaynağı olan "Önce İnsan” felsefesiyle ve bilinçli, güçlü bir kurum kültürüyle kütüphaneler verimliliğini artırabilirler. Amerikada'da yapılan araştırmalar, en iyi 
ve en başarılı kurumların ortak özelliklerinin hep kurum kültürünü oluşturmuş kurumlar olduğunu göstermektedir. Gücünü kendi çalışanlarının sadakatinden, zekasından alan ve kendine özgü bir kurum kültürü yaratan kurumların başarıları devamlı olur (Akıncı Vural, 2018: 2).

Her kurumun kendine ait bir kültürü vardır. Bu kültürü belirleyen unsurlar; kurumun kuruluş yılı ve faaliyet süresi, amaç ve hedefleri, kurumun bulunduğu çevre, çalışanların sosyoekonomik durumları, kurumun kapasitesi, çalışanların sayısı, teknoloji aletleri ve teknolojinin kullanımı, kurumdan beklentiler, sistemsel yapı gibi kültür unsurlarıdır. Kütüphanelerde kurum kültürü oluşumu, kurumun ve çalışanların amaç ve hedeflerine ulaşabilmeleri yolunda oldukça önemlidir. Yöneticilerciler, kurum kültürü oluşturabilmek için çalışanlarla iş birliği yapmalıdır. Bu iş birliği sonucunda, kurumda bilgi akışı iyi seviyeye getirilmelidir. Teknolojik imkanlardan ve elektronik kaynaklardan yararlanmalıdır. Alanında uzman ve eğitim almış, çalışanlarla sağlıklı bir iletişim süreci gerçekleştirecek kütüphaneciler olmadan kurum kültürü oluşturulamaz. Başarılı bir kurum kültürü olması için kütüphane çalışanları ve yöneticilerle arasında karşıllklı düşünce alışverişi olmalıdır (Önal ve Ekici, 2012:140-142).

Kütüphanede kurumsal kültürün oluşumunda yönetici önderlik eder. Yöneticiler, ilk başta kütüphane çalışanlarını motive etmelidir ve motive etme bazı nitelikler taşımalıdır. Bunlar:

- Kütüphanede çalışan bireylere, kurumun amacı ve hedefleri doğru bir şekilde anlatılmalıdır.

- Kütüphane yöneticisi, çalışanları, kütüphanecileri motive etmek istiyorsa onların da insan olduğunu unutmamalı, duygu, düşünce yapılarına önem vermelidir.

- Kütüphane içerisinde iletişim, çalışanlar arasındaki ilişki açısından oldukça önemlidir.

- İşbirlikçi sistem önemsenmeli ve uygulanmalıdır.

- Kütüphane çalışanları gözlemlenmeli, destek ihtiyacı olanlara yardım edilmelidir.

- Kütüphane içerisinde yönetici ve çalışanlar ortak kararlar alabilmelidir.

- Çalışmaları sonucunda başarı sağlayanlar ödüllendirilmelidir.

- Çalışanlar, kurallara uymadığında ya da tartışma veya tatsız olaylar olduğunda personel, zamanlaması iyi yapılacak şekilde uyarılmalı ancak bu uyarı ya da öğüt verme şeklinde değil bilgi verme şeklinde olmalıdır (Üstün, 1997: 27).

Kütüphanecilik mesleğinde, kullanıcıya hizmet etmek oldukça önemlidir. Kütüphane görevlisi ile kullanıcı arasında sürekli bir iletişim olmalı ve bu iletişim ile doğru bilgi aktarımı gerçekleştirilmelidir. Gerek halk kütüphaneleri, gerek araştırma kütüphaneleri, gerek çocuk kütüphaneleri gerekse de üniversite kütüphaneleri gerekli bilgiyi kullanıcıya verebilmeli, kullanıcıların fikir ve düşünceleri de dikkate alınmalıdır.

Kurumsal kültürün oluşabilmesi için kütüphaneci, kütüphanenin amacını, vizyon ve misyonunu çok iyi bilmelidir. Sağllklı bir hizmet sunabilmek için de kütüphane ile ilgili bilgi ve güncel konulanı çok iyi bilmelidir. Buna karşıllk kütüphane çalısanlarının beklentilerine, isteklerine geri dönüş yapmalı bu eksiklikleri yada beklentileri karşılanmalıdır. Oluşan eksiklikleri ya da beklentileri karşılarken gerekirse kurumu ilgilendiren değişiklikler yapılmalıdır. Bu bağlamda kurumsal kültüre bir takım etmenlerin etkisi vardır. Bunlar ( Bayter, 2008: 16):

- Güçlü liderlerin etkisi,

- Kütüphanenin geçmişi ve geleneği,

- Teknolojik ürünler ve hizmetler,

- Hizmet kullaniciları,

- Kütüphanenin beklentileri,

- Bilgi erişim ve kontrol sistemleri,

- Yasalar ve çevre,

- Organizasyon ve kaynaklar,

- Hedefler ve değerler. 
Kütüphanelerde yönetim ve kurum kültürü oluşturmakta bir takım sorunlar da yaşanmaktadır. Bu sorunlar; yabancı dil, kütüphane bütçesi, tecrübeli kütüphanecilerin bulunmayışı, bir kurum tarafindan belirlenmiş kütüphane politikasının yokluğu, kütüphanecilere uygun kadro bulunmayışı, yöneticilerin yasal yetkilerinin sınırlı olması, kütüphane hizmetlerinin çok çeşitli olması, ulusal bir kütüphanecilik politikasının olmayışı, üst yöneticilerin kütüphaneye bakış açısı, personelin yeni teknolojilere uyum problemleri ve kullanıcılara ilişkin problemlerdir (Çelik, 2014. :327).

\section{Kütüphane ve Kurumsal Davranış}

Toplumdaki her kuruluş gibi kütüphaneler de belli toplumsal gereksinimleri karşılamak için kurulmuştur. Kuruluş gereklerine ve ona bağlı olarak belirlenecek amaçlarına uygun faaliyetlerde bulundukları sürece, yaşamlarını sürdürürler. Genelde kütüphanelerin var oluş nedeni, her tür kayıtlı bilgi kaynağı ile bilgi gereksinimi olan kullanıcılar arasında uygun bir bağlantı kurmak; aynı zamanda bilgi kaynaklarında ve kullanıcılara zaman içinde ortaya çıkacak değişmeleri de göz önüne alarak, bağlantı işlevlerini, bilgi kaynaklarını sağlama ve düzenleme ile onlardan yararlandırma diye özetlenebilecek temel hizmetler yoluyla gerçekleştirmektir. Bu özellikleriyle, kütüphaneler kendine özgü kurumsal davranışta bulunurlar(Yontar, 1995, s. XI).

Kurumsal davranış, kütüphane iletişimini, kurum kültürünü, kurumdaki yenilik ve değişimleri kapsayan bir çatıdır. Kütüphanede kurumsal bir davranışın olabilmesi için cevaplanması gereken sorular vardır. Bunlar:

- Personelin aynı durumlarda farklı davranış sebepleri nelerdir?

- Değerler, personelin davranışını nasıl etkilemektedir?

- Personeli daha iyi hizmet için neler motive eder?

- Bazı personel diğerlerine göre neden daha fazla performans gösterir?

- Hangi faktörler personelin isslerini sevmelerini sağlar?

- Takım çalışmasının verimliliğini belirleyen faktörler nelerdir?

-Kurumsal verimliliği en üst düzeye çıkarmak için kütüphane nasıl düzenlenir? (Bayter, 2008: 15).

Kurumsal davranışın amacı kütüphane çalışanlarını kontrol etmek ve onların davranışlarını anlayarak geleceğe yönelik tanımlar yapmaktır. Kütüphane çalışanının, çalışma hayatı boyunca edindiği tecrübe ve beceriler, çalışanların tutum ve davranışlanı, kullanıcılara yönelik davranışları, çalışma ve performansları üzerinde ve kişiliği üzerinde de etkili olmaktadır ( Bayter, 2008: 15).

Kütüphane çalışanlarının motivasyon süreci, çalışma süreleri, ücretleri, çalışma koşul ve ortamı, işten aldığı doyum, yaşı, cinsiyeti, stres vb. durumlar hem kurum kültürünü, hem kullanıcılarla olan ilişkilerini hem de kurumsal davranışlarını etkilemektedir. Bu şartlar sağlanmadığı takdirde kütüphaneci, bilgi aktarımını gerçekleştiremez. Kullanıcılara uygun hizmeti verip sağlıklı bir kurumsal bağlılık gerçekleştiremez. Bu da kurumun başarısını ve gelişimini olumsuz yönde etkiler. Dolayısıyla kurum ortak bir amaca yönelik hareket eden ve grup üyelerini bütünleştirici politikasından çıkış olur. Söz konusu durum sadece bir çalışanı değil kurumun genelini etkisi altına alır.

\section{Kütüphanenin Kurumsal Kültürünün Değişimi}

Gelişen teknoloji ile kütüphaneler artık geleneksel yöntemlerin yanı sıra dijital ve teknolojik kaynakları da kullanmaktadır. Bu kaynaklar hem kullanıcının bilgiye daha hızlı ve pratik bir şekilde, zamandan tasarruf ederek ulaşmasını sağlamakta, hem de kütüphane sorumlusu için faydalar sağlamaktadır. Her geçen gün daha fazla kütüphane kişiye özel içerikler ve günlükler aracılı̆̆ ile kişiselleştirilmiş haberler sunmaktadır. Kullanıcılar kütüphane personeli ile e-posta ya da kısa mesaj sistemleri ile iletişim kurabilmekte, kütüphane kaynakları için yorum yapabilmekte veya etkileşimli bir ortamda kaynakları derecelendirebilmektedir. Kütüphanelerin web sitelerindeki arama kısmını kullanarak kullanıcılar, kütüphane kaynaklarına hareket halindeykende ulaşabilmektedirler ( Tonta, 2009: 749). 
Kütüphanelerin teknoloji ile buluşması sonucu e-kütüphane faaliyetleri hız kazanmış ve daha çok tercih edilir hale gelmiştir. Kullanıcılar teknoloji sayesinde istedikleri kitapları e-kopya olarak Amazon veya diğer çevrim içi kitapçılardan satın alarak rahatlıkla kendi e-kütüphanelerini oluşturup okuyabilmekte istedikleri zaman erişebilmektedirler. Aynı şekilde sattn aldıkları bu kitapları e-bay vb. alım-satım yerlerinde tekrar satabilmektedirler (Tonta, 2009: 751).

Bütün bu teknolojik gelişmeler kütüphanelerin, istek ve talepler doğrultusunda değissip, gelişebileceklerini göstermektedir. Gelişen teknoloji, bilgi birikimleri, arz-talep doğrultusunda kurumsal devamlılığını sağlamak için kütüphanelerde de kurumsal kültürün değissim ve gelişim ihtiyacını göstermektedir. Kütüphanenin kurumsal kültürü şu nedenler doğrultusunda değissebilir (Bayter, 2008: 17-18-19).

1. Kütüphanenin yeni amaç ve hedefleri var mı?

2. Hedefler bugünün bilgi hizmetleri ortamında bir anlam ifade ediyor mu?

3. Mevcut kaynaklar nelerdir?

4. Kütüphane kurum yapisı nedir?

5. Çalışanlar arasında olması gereken etkileşim nedir?

6. Mevcut etkileşim nelerdir?

7. Ödül ve ceza mekanizmaları nasıl işler?

8. Kütüphane nasıl yönetilir?

9. Esnek problem çözme stratejileri nelerdir?

10. Geri iletim sistemleri zamanl, objektif ve doğru mu?

11. Kütüphane ne kadar bürokratik?

12. Genel psikolojik iklim nedir?

13. Kütüphane içerisindeki yetki kaynakları nelerdir?

14. Kütüphanenin değişik düzeylerindeki yetki limiti nedir?

15. Değişim destekçileri var mı?

16. Kütüphane içerisindeki yetki ne şekilde kullanıllyor?

17. Kütüphane içindeki fikir liderleri kimlerdir?

18. Kullanılan teknolojinin kurumsal davranış üzerinde önemli rolü var mı?

19. Hizmet kullanıcılarının ihtiyaçlanına etkili bir şekilde cevap verebiliyor muyuz?

20. Çalışanların ihtiyaçlarına gerçek anlamda cevap veriyor muyuz?

21. Sistemlerimiz hedeflerimizi destekleyecek nitelikte mi?

\section{Sonuç}

Bilginin hızla değişmesi doğal olarak bilgiyi ve bilgi kaynaklarını mevcudunda barındıran kütüphanelerinde bu yenilenme sürecine katılarak bilgi hizmetlerini en uygun şekilde sunmas1 gereklidir. Sürekli güncellenen dünyada kurumların kendilerini yenileyebilmeleri kurumsal alt yapının yanında kurumsal kültürün oluşması ile gerçekleşecektir. Kütüphanelerin bilgi hizmetlerini en iyi kalitede sunacak ve talep edilen bilgiye ulaşmada insanlara yardımcı olacak olan kütüphane personelinin, kurum kültürü çerçevesinde kendilerini geliştirmeleri gerekmekmektedir. Kurum kültürü, kütüphane kurumunun başarısının altında yatan en önemli nedenlerden biridir. Kurum kültürü oluşturmak, kütüphanede çalışan personele kurumsal bir davranış kazandırmak, bireylerin ihtiyaç ve beklentilerini karşılamaktan geçmektedir. Bu kültür öğeleri veya unsurları ne kadar yerinde ve doğru bir şekilde karşılanırsa, kurum o kadar çok gelişecek ve tercih edilir olacaktır.

Kütüphanelerde çalışanlar, kullanıcılara en iyi hizmet için çaba göstermelidir. Bir bireyden diğerine bilgi ve deneyimin aktarılması ve paylaşılması süreci olan kurumsal kültür; açık, anlaşılır ve doğru işleyen kanallar biçiminde oluşmayan bir kütüphanede etkili bir hizmetten ve iyi bir yönetimden söz edilemez. Buna ilaveten çalışanlar, çeşitli biçimlerde etkileşim kurarak birbirlerini etkilemekte ve diğer çalışanların da bu amaçlara katkılarını arttırmaya çalışmaktadır. Bütün bu faaliyetler kütüphanelerin yapıları, amaçları, değerleri ve politikaları tarafindan desteklenmekte veya kısıtlanmaktadır. İşte bütün bu kütüphane içindeki faaliyetler sonuçta kütüphanenin kurumusal kültürünü oluşturmaktadır. Kütüphanenin kurumsal kültürü, çalışanlarının tutumu, davranışı ve 
performanslarıyla ortaya çıkmaktadır. Kütüphane içindeki kurumsal kültürü anlamaya çalışarak, geleceğe dönük tahminlerde bulunup kütüphane kurumunun başarısı artırllabilir.

\section{Kaynakça}

Akıncı Vural, B. Z. (2018). Kurum Kültürü. İstanbul: İletişim Yayınlan.

Armstrong, M. (1990), Management Processes and Functions. London: Institute of Personnel Development.

Bakan, İ., Büyükbeşe, T. ve Bedestenci, Ç. (2004). Örgüt Sırlarının Çözümünde Örgüt Kültürü:Teorik Ampirik Yaklaşım. İstanbul: Aktüel Yayınları.

Balmer, M. T. John and Stephen A. Greyser; (2003). Revealing the Corporation. London: Routledge.

Bayter, M.(2008). Kütüphanelerin Örgütsel Davranışın Gelişimi. Türk Kütüphaneciliği: 22(1), 324.

Boyac1, F.M. (2010). Örgütsel Bağlllı̆̆ın Arttırılmasında Etkin İletişim- Bir Uygulama.Yüksek Lisans Tezi. Muğla, Muğla Üniversitesi.

Cansu, C. O. (2006). Örgüt Kültürü ile Örgütsel İletişim İlişkisi ve Bir Şirket Uygulaması, Yayınlanmamış Yüksek Lisans Tezi. Ankara: Gazi Üniversitesi Sosyal Bilimler Enstitüsü.

Cohen, D. and Prusak, L. (2001). Kavrayamadığımız Zenginlik: Kuruluşların Sosyal Sermayesi, Çev: Ahmet Kardam. İstanbul: Mess Yayınları.

Çağlar, İ. (2001). Yönetim-Kültür Bağlamında Türk Yönetim Modelinin Saptanmasına Yönelik Kavramsal Bir Çalışma. Gazi Üniversitesi İ.̇.B.F. Dergisi, 3(3), 125-148.

Çakın, İ. (1986). Kütüphanenin Toplumsal Konumu ve İşlevleri. TKDB:35 (1), 9-18.

Çelik, S. (2014). Türkiye'deki Üniversite Kütüphanelerinde Personel Yönetimi. Ankara: Siyasal Kitabevi.

Deal, T. E., \& Kennedy, A. A. (2000). Corporates Cultures: The Rites and Rituals of Corporate Life. New York: Basic Books

Değirmenci, M. (2007). Amaçlı Canlılar: Yönetimde Üçüncü Nesil Sistem Düşüncesi. İstanbul: Hiperlink Yayınları.

Dina, T. and Olowosoke, G. O. (2018). The Effect of Motivation and Job Performance on Library Personnel Effectiveness in Universities Libraries in Nigeria. Library Philosophy and Practice (e-journal).

Durğun, S. (2006). Örgüt Kültürü ve Örgütsel İletişim. Mersin Üniversitesi Eğitim Fakültesi Dergisi: $3,2$.

Erdem, A. R. (2003). Üniversite Kültüründe Önemli Bir Unsur: Değerler. Değerler Eğitimi Dergisi, 1(4), 55-72.

Erdem, O., Dikici, M. (2009). Liderlik ve Kurum Kültürü Etkileşimi. Elektronik Sosyal Bilimler Dergisi, 8(29), 198-213.

Fidan, M.(2011). Yeni Kurulan Üniversitelerde Çalışanların Örgüt Kültürü Algısı: Bilecik Üniversitesi Örneği. Yüksek Lisans Tezi. Bilecik, Bilecik Üniversitesi

Greenberg, J. and Baron, R. A. (1990). Behavior in Organizations. New Jersey: Prentice Hall, Inc

Goffee, R. and Jones, G. (2002). Kurum Kültürü, Çev.: Kıvanç Kutmandu. Ankara: Kapital Medya Hizmetleri.

Hofstede, G., Hofstede, G. J., \& Minkov, M. (2010). Cultures and Organizations: Software of the Mind. McGraw-Hill.

Kaptan, S. (1998). Bilimsel Araştırma ve İstatistik Teknikleri. Ankara: Bilim Teknik Yayınları.

Kilmann, R. H. (1985). Corporate Culture: Managing the Intangible Style of Corporate Life May Be the Key to Avoiding Stagnation. Psychology Today, 19(4), 62-68.

Kozlu, C. (1986). Kurumsal Kültür: Amerika, Japonya ve Türkiye: Başarılı Firma Yönetimlerinde Kurumsal Kültürün Rolü. İstanbul: Bilkom Yayıncılık. 
Bayter, M (2019). Bilgi hizmetlerinin gelişmesinde kütüphanelerde kurum kültürünün oluşmasının önemi. Journal of Human Sciences, 16(3), 844-856. doi:10.14687/jhs.v16i3.5771

Kurulgan, M ve Paşaoğlu, D. (2013). Bilgi Profesyonellerinin Bilgi Teknolojisi Kullanma Eğilimlerinin Belirlenmesi Üzerine Üniversite Kütüphanelerinde Yapılan Karşılaştırmalı Bir Araştırma. Türk Kütüphaneciliği: 27 (1) 52-78.

Lewin, K., Lippit, R., \& White, R. K. (1939). Patterns of Aggressive Behavior in Experimentally Created 'Social Climates'. International Journal of Social Psychology, 10, 271- 299.

Muratoğlu, V. ve Özmen. (2006) Eğitim Örgütlerinde Bilgi Yönetimi Stratejileri- Yaş ve Okul Türü Değişkenlerine Göre Eğitimci Görüşleri (Tunceli İl’i Örneği) Erişim adresi http://ab.org.tr/ab06/bildiri/85.pdf

Önal, İ.H. ve Ekici, S.(2012). Okul Kütüphanecilerinin Görüşlerine Göre Okul Kültürü Değerlendirmesi. Bilgi Dünyası 13 (1) 138-164

Peters, T. J., \& Waterman, R. H. (1995). Mükemmeli Arayış Yönetme ve Yükseltme Sanatı. İstanbul: Altın Kitaplar.

Robbins, S.P. ve Judge, T.A. (2013). Örgütsel Davranış. Ankara: Nobel Kitabevi.

Sabuncuoğlu, Z. ve Tüz, M. (1998). Örgütsel Psikoloji. Bursa: Alfa Yayınları.

Satuk, A. (2006). Örgütsel Başarı da Örgüt Kültürünün Etkisi. Yüksek Lisans Tezi. Kars. Kafkas Üniversitesi.

Schein, E. H. (1990). "Organizational Culture". American Psychologist 145 (2, February 1990).

Schein, E. H. (2004). Organizational Culture and Leadership. San Francisco, Calif. Jossey-Bass.

Schermerhorn, J. R.; J. G. Hunt and R. Osborn (2008). Orgazinational Behaviour. New York: John Wiley \& Sons Ġnc.

Şahin, A. (2010). Örgüt Kültürü-Yönetim İlişkisi ve Yönetsel Etkinlik. Maliye Dergisi 159. 21-36.

Şişli, G. ve Köse, S. (2013). Kurum Kültürü ve Kuramsal İmaj İlişkisi: Devlet ve Vakıf Üniversiteleri Üzerinde Bir Uygulama. Erciyes Üniversitesi İktisadi ve İdari Bilimler Fakültesi Dergisi, Sayı: 41, 165-193.

Tonta, Y. (2009). Dijital Yerliler, Sosyal Ağlar ve Kütüphanelerin Geleceği. Türk Kütüphaneciliği 23 (4) $742-768$.

Tural, R. (2009). Örgüt Kültürünün Çalışanların Verimliliği Üzerindeki Etkileri ve Bir Uygulama. Yüksek Lisans Tezi. Niğde: Niğde Üniversitesi.

Uslu,C.(2010). Öğretim Elemanı Algılarına Göre Örgüt Kültürü: (Ege Üniversitesi Örneği). Yüksek Lisans Tezi. İzmir: Ege Üniversitesi.

Üstün, A. (1997).Kütüphanecilik Mesleğinde İç İletişim ve Motivasyon. Türk Kütüphaneciliği:11. 20-28.

Yılmaz, B. (2003). Toplumsal İletişim ve Kütüphane. Hacettepe Üniversitesi Edebiyat Fakültesi Dergisi. 20 (2) 11-30

Yontar, A. (1995) Kütüphane ve Belge-Bilgi Merkezlerinde Bilimsel Yönetimin Önemi. İstanbul: Türk Kütüphaneciler Derneği İstanbul Şubesi.

\section{Extended English Summary}

Like any other organization in the society, libraries have been established to meet certain social needs. As long as they provide services in accordance with the requirements of the organization and the objectives to be determined depending on it, they may continue to be sustainable. The reason for the existence of libraries in general is to establish an appropriate connection between any registered source of information and the users in need of information; to provide connection functions through basic services that can be summarized as providing and organizing information resources and taking advantage of them, taking into account changes in information resources and users over time.

In this information age, providing faster and safer access to information and meeting the need for information is the sine qua non of social and cultural success. Access to information also leads to interaction and communication between people. The basic function of the library 
institution is to meet the information needs of individuals. As in every institution, it is possible to talk about a corporate culture within the library. The presence of corporate culture in the library is the result of communication between employees, expectations, common values, common goals, attitudes and behaviors. Thanks to this culture, the needs and expectations of the library users are more successful and the foundations of healthy communication with the users are established. A library with a corporate culture fulfills the needs of the users in a planned and programmed way.

In order to have a library culture, the personnel must be correctly selected and organized among the staff. This organization varies according to the number of users in the libraries, the policies of the institution, the location of the library and the integrity of the collection. Establishing a corporate culture, giving the personnel working in the library a corporate behavior, meeting the needs and expectations of individuals is passed. The more appropriate and correct these cultural elements or elements are met, the more developed and preferred the institution will be.

Personnel management is a very important concept in corporate culture. Cooperation, trust and friendly relations between the personnel should be ensured. This enables staff to build corporate commitment, corporate culture and corporate behavior. The development of the institution is the result of the efforts and efforts of the staff. Therefore, human resources and personnel are important in the organization. Increasing the productivity of the personnel and revealing the personnel skills are the result of a good management activity. Personnel management is directly concerned with human-related issues such as the provision of personnel, training, development, financial satisfaction, adaptation to the organization, and the provision of health and protection guarantees in order to achieve the purpose of an institution. Accordingly, each library has a number of management and culture characteristics. University libraries, school libraries, public libraries and so on. management and personnel management in library types are very important for the establishment of corporate culture.

Corporate culture is one of the most important reasons underlying the success of the institution, the library and the communities. Establishing a corporate culture, giving the personnel working in the library a corporate behavior, meeting the needs and expectations of individuals is passed. The more appropriate and correct these cultural elements or elements are met, the more developed and preferred the institution will be.

The basic function of the library institution is to meet the information needs of individuals. As in every institution, it is possible to talk about a corporate culture within the library. The presence of corporate culture in the library is the result of communication between employees, expectations, common values, common goals, attitudes and behaviors. Thanks to this culture, the needs and expectations of the library users are more successful and the foundations of healthy communication with the users are established. A library with a corporate culture fulfills the needs of the users in a planned and programmed way.

The most important role in the formation of corporate culture in libraries falls to the library manager. Because the manager should be adopted by the working individuals, be a good guide for them, and be able to create a system that is permanent and will not lose its validity. It should be a good role model for employees and be able to motivate employees. They should be able to create team spirit within the library and instill the spirit of unity and solidarity to employees. With this atmosphere, employees should strive for the best service to the users. In addition, staff should interact with each other in a variety of ways and try to increase their contribution to objectives. The structures, objectives, values and policies of libraries should be supported in the formation of corporate culture. 